\title{
An integrated machine learning approach reveals geochemical controls on microbial electron- transfer protein abundance
}

JOY BUONGIORNO ${ }^{1 *}$, DONATO GIOVANNELLI ${ }^{2}$, MAARTEN DEMOOR ${ }^{3}$, PETER BARRY ${ }^{4}$, MATTHEW SCHRENK $^{5}$, KAREN G. LLOYD ${ }^{6}$, SHWETA NAKAR ${ }^{7}$, SHAUNNA MORRISON $^{1}$, ROBERT HAZEN ${ }^{1}$

${ }^{1}$ Earth and Planets Division, Carnegie Institution of Washington, Washington, DC, USA

${ }^{2}$ Department of Biology, University of Naples "Federico II", Naples, Italy

${ }^{3}$ Volcanological and Seismological Observatory of Costa Rica Universidad Nacional, Costa Rica

${ }^{4}$ Marine Chemistry and Geochemistry Department, Woods Hole Oceanographic Institution, Woods Hole, Massachusetts, USA

${ }^{5}$ Department of Earth and Environmental Sciences, Michigan State University, USA

${ }^{6}$ Department of Microbiology, University of Tennessee, Knoxville, USA

${ }^{7}$ Tetherless World Constellation, Rensselaer Polytechnic Institute, Troy, New York, USA

*email: jbuongiorno@carnegiescience.edu

Planetary redox shifts on early Earth spawned microbial evolution of new electron-transfer processes mediated by oxidoreductase enzymes. Many oxidoreductase co-factors include transition metals, which are primarily sourced from volcanic emissions. Our understanding of how volcanically-mediated metals affected the trajectory of microbial evolution can be expanded by tracing the abundance of oxidoreductases in modern environments within the framework of volcanic regime and in situ transition metal chemistry.

Here, we conducted a comparative analysis of nearly 1,000 metagenomes collected from volcanically-influenced sites typified by differences in their magmatic water content, fluid evolution, and metal emission signatures. Co-correlation networks of several hundred oxidoreductases revealed that volcanic arcs are distinct from hydrothermal vents. Enzyme cliques were included in a machine learning approach alongside co-located transition metal chemistry to identify the key geochemical controls of oxidoreductase distribution. Results show that iron and manganese are crucial geochemical features. 